\title{
Energy Drink Consumption in the Australian Construction Industry: A Risky New Trend?
}

\author{
Rebecca Loudoun ${ }^{1}$ and Katherine Markwell ${ }^{2}$
}

\begin{abstract}
Construction workforces' health behaviors have received little attention compared with work injury risks and management. Formulated caffeinated beverage (FCB) (energy drink) consumption is relatively new to construction sites and excessive consumption may have effects on both health and safety owing to known short- and long-term physiological responses. This study contributes to understanding drivers and deterrents of caffeine and FCB consumption in construction. Data were collected from workers at six construction sites in Queensland, Australia, using mixed-method research design involving semistructured interviews (70) and quantitative surveys $(n=250)$. Convergent interviewing underpinned by the theory of reasoned action was used to analyze qualitative interviews. Bivariate logistic regression analyses were conducted to examine determinants of caffeine and FCB consumption. Work hours were associated with caffeine consumption $>210 \mathrm{mg} /$ day $(\beta=-0.046, p=0.037)$. Qualitative results indicate energy drinks are consumed widely and regularly on site, with stress and attempts to manage the pace, timing, and intensity seen as drivers for consumption. In combination, these findings suggest management of FCBs on construction sites requires more attention as a potential health hazard. DOI: 10.1061/(ASCE)CO.1943-7862.0001339.
\end{abstract} (c) 2017 American Society of Civil Engineers.

Author keywords: Labor and personnel issues,

\section{Introduction}

Like most industrialized countries, the construction industry in Australia has a reported higher incidence of short-term, risky alcohol consumption than most other industries and has long been associated with a drinking culture (Alwan 2011; Berry et al. 2007). Explanations of why this drinking culture exists generally revolve around the entrenched work organization practices in the industry and the nature of the workforce. Construction is a male-dominated sector with a large proportion of young workers (ABS 2011); men are known to adopt less healthy lifestyles and less health-promoting behavior than their female counterparts (Courtenay 2000; Levant et al. 2009) and young males are more likely to drink to excess than older adults (Australian Institute of Health and Welfare 2011). It is well accepted that the work environment in construction is highly demanding and stressful (Chan et al. 2012; Wang et al. 2016), with longer than average working hours compared with most other industries (ABS 2013). General stresses on site are compounded by tight deadlines and severe financial penalties for failing to meet set targets resulting in a cycle of activity with peaks and troughs in production requirements and work hours and limited fixed or long-term employment (Lingard et al. 2012). Consuming alcohol to alleviate tension resulting from exposure to these work stressors is a common practice (Bowen et al. 2013) and consistent with the widely cited Tension Reduction Theory (Conger 1951; Pabst et al. 2010).

\footnotetext{
${ }^{1}$ Senior Lecturer, Dept. of Employment Relations and Human Resources, Griffith Univ., Nathan 4111, Australia (corresponding author). E-mail: r.loudoun@griffith.edu.au

${ }^{2}$ Sessional Lecturer, School of Exercise Science, Faculty of Health Sciences, Australian Catholic Univ., P.O. Box 456, Virginia, QLD 4014, Australia. E-mail: katherine.markwell@acu.edu.au

Note. This manuscript was submitted on September 20, 2016; approved on February 6, 2017 No Epub Date. Discussion period open until 0, 0; separate discussions must be submitted for individual papers. This paper is part of the Journal of Construction Engineering and Management, (C) ASCE, ISSN 0733-9364.
}

This article focuses on evidence for a new drinking behavior risk in construction, formulated caffeinated beverages (FCBs) (Australia New Zealand Food Standards Code Standard 2.6.4), commonly termed energy drinks. The health effects of FCBs have not been fully established, however it is known that long-term exposure to the various components of these drinks is likely to result in significant alterations in the cardiovascular system (Higgins et al. 2000). Energy drink consumption is also associated with alcoholrelated problems and dependence (Arria et al. 2011). Work safety is often researched in the construction sector because it has higher injury rates than most other sectors (Loudoun 2010; Safe Work Australia 2012). However, as a research topic, construction worker health and well-being has received scant attention to date (Hengel et al. 2013), possibly owing to the clear measurable costs associated with injury (Iles et al. 2012). The current research investigates consumption patterns of caffeine in general, and FCBs in particular, with a view to providing insight into drivers and deterrents for consumption and impacts of consumption.

\section{Formulated Caffeinated Beverages in Construction}

In Australia, formulated caffeinated beverages are consumed across the population (ABS 2012). Food Standard 2.6.4 regulates the consumption of caffeine per beverage between 145 to $320 \mathrm{mg} / \mathrm{L}$ of caffeine (Australia New Zealand Food Standards Code Standard 2.6.4). Food composition data approximate FCBs to have $32 \mathrm{mg} / 100 \mathrm{~g}$ of caffeine compared with cola soft drinks with $9 \mathrm{mg} / 100 \mathrm{~g}$ (FSANZ 2011). While $\mathrm{mg} / \mathrm{mL}$ of caffeine is regulated in FCBs in Australia, the total amount of caffeine per serving size is not (Pollard et al. 2015). Soft drink serving volumes have increased in size in Australia (Hector et al. 2009), including FCBs. In this study, 600-mL bottles or cans of energy drinks were identified as available in vending machines in all participating construction sites. Considering these elements together, FCBs have the potential to be a significant source of caffeine toxicity, which is reported as rising in Australia, with severe side effects including cardiac and 
neurological toxicity, palpitations, tremor, seizures, hallucinations, and arrhythmias (Gunja et al. 2012).

In the Australian population, men consume more FCBs than women on average with $8.3 \mathrm{~g} /$ day consumed compared with $2.3 \mathrm{~g} /$ day (ABS 2012). Construction may have a higher consumption than other groups when factoring in its predominantly younger male demographic, which is that targeted by FCB manufacturers with claims their products provide "... psychoactive, performanceenhancing and stimulant drug effects" (Reissig et al. 2009, p. 7). The colloquial reference of FCBs as energy drinks further promotes perceptions of their stimulant effects. For U.S. college students, reasons cited for FCB consumption include insufficient sleep and to increase energy (Malinauskas et al. 2007). In U.S. military personnel, intake was cited as being for improving mental alertness, mental endurance, and physical endurance, with $65 \%$ of those reporting use also reporting a side effect (Stephens et al. 2014).

It is well known that young males are the target group for FCBs, but little is known about their use in construction. There can be no doubt that consumption of FCBs is on the rise, with a $351 \%$ increase in consumption between 2001 and 2010 (Canadean 2011) and, in broader research on young males, higher risk-taking and masculinity scores were associated with FCB consumption (Miller 2008). Despite this research, consumption patterns among construction workers of FCBs are unknown. For example, it is not known whether construction workers disproportionately and excessively use these products on their own or together with other caffeine beverages such as coffee and milk-based drinks, or the possible implications for health and safety on site should this be the case. Information about beverage consumption and levels of consumption in construction is important to characterizing industry safety risks as well as health risks.

There are several safety risks that could be hypothesized to exist with high caffeine consumption in the construction industry. For example, excessive caffeine consumption could cause incidents if a palpitation or tremor occurred when working. Caffeine consumption is also known to be sleep disruptive (Roehrs and Roth 2008) and reduce sleep homeostasis and sleepiness (Landolt et al. 2004). Given long working hours and reduced sleep hours in construction projects, increasing sleep debts further by consumption of caffeine may reduce recovery further (Lingard et al. 2008; Townsend et al. 2012). Poor mental health is also a known risk among construction workers (Love et al. 2010; Wang et al. 2016). In Australia, the only caffeine recommendation for nonpregnant adults is that consuming more than $210 \mathrm{mg}$ daily may increase anxiety (Smith et al. 2000), which is marginally above one standard 600-mL can of FCB (FSANZ 2011).

From the viewpoint of physical health and chronic disease risk, FCBs might also pose risks. Construction workers have higher rates of cardiovascular risk factors including obesity, high blood pressure, smoking, and harmful alcohol consumption (Alwan 2011) than those of the standard population. Energy-dense and nutrient-poor foods and beverages contribute to the development of obesity and high blood pressure. Obesity is frequently estimated with body mass index (BMI) (Flegal et al. 2012), a commonly used measure of body fat based on height and weight that applies to adult men and women. Sugar-sweetened beverages including soft drinks have been linked to obesity (Malik et al. 2010). Formulated caffeinated beverages fit within the soft drink category (Hector et al. 2009). The avoidance of cordials and sports drinks is recommended in hydration strategies due to their high energy (caloric) content (Hedrick et al. 2012). Formulated caffeinated beverages have greater sugar content on average than both cordial and sports drinks (FSANZ 2011), therefore they need to be avoided in hydration strategies irrespective of caffeine. Given this research, it seems reasonable to conclude FCB consumption could further exacerbate construction workers' risk of dehydration in the short term and developing cardiovascular disease (CVD) and diabetes in the long term through increased energy intake.

In sum, this review of existing evidence of the implications of FCB consumption on work health and safety highlights that there are many unknowns about their long- and short-term use in construction. Nonetheless, in combination the existing evidence suggests there are good reasons for not wanting use to extend to misuse and dependence. Furthermore, it suggests that investigation to understand consumption patterns and drivers is needed to develop effective strategies to manage consumption on site. Investigation to understand consumption patterns and drivers is needed to develop these strategies. The theory of reasoned action (TRA), which explains behavior as determined by a person's evaluations of the behavior (attitude) and perceptions of social pressure (subjective norm), offers a guiding framework for such an investigation (Ajzen and Fishbein 1980).

The theory of reasoned action has long been used as a model to predict behavioral intentions and/or behavior in the field of health (Fishbein 2008; Godin and Kok 1996; Head and Noar 2014). Additional variables have been proposed and tested for inclusion in, or expansion of, the theory since it was first postulated almost 40 years ago. However, at its most simple level, a reasoned action approach to the explanation and prediction of behavior assumes that people's behavior follows reasonably from their beliefs in favor of or against performing the behavior (Ajzen and Fishbein 1980). Applying the reasoned action approach to FCB consumption, a simple explanation of an individual's motivation to drink would center on their positive personal judgments about the perceived consequences of performing the behavior (such as "I expect to have a lot more energy if I have a FCB") together with their views about what important specific referent individuals think they should do (such as "more experienced people than me drink energy drinks on site, therefore it must be a good idea"). These beliefs represent an important component of motivation to drink, while negative judgments (such as "I expect to have health problems if I consume large amounts of FCBs" or "my site manager only drinks water on site, therefore I should too") provide motivation to restrain.

Drawing on TRA, the present study develops existing knowledge by investigating perceived influences and drivers of caffeine and particularly FCB consumption in Queensland, Australia. The research draws on data from managers and employees of both principal contractors and subcontractors in project-based construction. The analysis seeks to provide greater insight into patterns of consumption on site as well as influences and perceived impacts of consumption. Previous research has identified time pressures and working hours as impacting health decisions in construction (Townsend et al. 2016) and work hours usually differ by trade with structural trades generally having longer work hours in Australia than finishing trades (ABS 2011). Work influences are focused on in this study because these are potential modifiable determinants. Demographic variables including age and obesity were included for the previously stated reasons. Salary was also included because food costs impact purchasing and salary may therefore be a driver of consumption (Andreyeva et al. 2010). Therefore, associations between work hours and trade type and caffeine and FCB consumption were investigated.

\section{Methodological and Theoretical Framework}

This examination of caffeine and FCBs consumption in construction adopted Ajzen and Fishbein's (1980) theory of reasoned 
action. At its core, this theory holds that an individual's assessment of outcome expectations determines behavior. Whether perceptions about the desirability and likelihood of an outcome are valid is irrelevant to determining behavior; to influence behavior, the beliefs simply need to be held. This research, therefore, combined information about patterns of FCB consumption in construction with perceptions about drivers of these patterns as well as their influence on activities and behaviors on worksites.

This focus, as well as the chosen theoretical approach, were considered when deciding on which methodological strategy to adopt for the study. A mixed-methods pragmatic approach (Onwuegbuzie and Leech 2005) was adopted with both qualitative and quantitative data because this approach offers the opportunity of minimizing limitations of a single approach by combining methods with complementary strengths (Abowitz and Toole 2010). The quantitative study allowed the collection of data about consumption patterns relevant to a wide cross section of ages and trades, while the qualitative responses provided in-depth, rich information about perceived influences and drivers of consumption.

Phenomenology guided the qualitative research process because this methodology promotes investigation of the lived experiences of participants under investigation (Creswell 2007). It also encourages an interdisciplinary approach to the topic under investigation, which was deemed necessary given the limited research in this area and the aim to draw insights and perceptions from a wide range of managers and employees.

\section{Method}

Construction workers and managers on six construction projects in Brisbane, Australia, participated in the study. These projects were chosen to ensure consistency across build type and size. All sites were completing project-based, large mulitstory builds of commercial office space or mixed residential and retail space. Qualitative and quantitative data were collected between mid-2014 and mid2015. Principal contractors and union delegates on each site made the initial request for participation in the study to all subcontractors and principal contractor employees at start-up meetings and lunch breaks. The researchers used subsequent lunch breaks to follow up these requests and distribute surveys. Contact details were collected in surveys and interviews were conducted at a later date during work hours using a semistructured approach as described by Fontana and Frey (1994).

Twenty-eight contractor managers, 15 subcontractor managers, and 27 trades workers were interviewed individually (45 in total) or in small groups (25 in total). A purposive sampling strategy was used to ensure representation from each level of the hierarchy and from the major trades - concreters, electricians, plasterers, painters, plumbers, bricklayers, and formwork carpenters-and position titles at each level-contracts managers, site managers, site-based and corporate work health and safety managers, and officers from the principal contractor and from subcontracting firms, supervisor, and team leaders. All interviewees were male, reflecting the current usual worksite demographic of the industry.

Interviews began with broad questions about healthy lifestyle behaviors and health and well-being to introduce the topic and because this study formed part of a larger study about nutrition and dietary habits in construction. Using a similar order, participants were then asked specifically about beverage intake on site; any perceptions of effects of beverages on site, particularly safety and productivity; site influences; and barriers or facilitators for beverage consumption. Managers were also asked about their role and any perceived responsibilities with regard to beverage intake and productivity and safety on site. Three researchers performed the interviews; notes were made during the interviews to assist with postinterview discussions, but interviews were also audio recorded and subsequently transcribed. Data collection continued until the researchers reached theme consensus and all researchers agreed no new information was emerging from the interviews and repetition of concepts became consistent.

Quantitative data were collected on demographic information, work information, and beverage consumption. Data about drink consumption type, frequency, and amounts were collected using the previously validated BEV-15 survey (Hedrick et al. 2012), with 15 items summing the frequency per week by the amount consumed each time. The BEV-15 was modified to 12 items by the project's research dietitian (Katherine Markwell) to include drinks, terms, and volumes consistent with the Australian setting, and to allow caffeine consumption calculation. Respondents were asked whether drinks were consumed in combination with food or as a meal replacement. Demographic information about age, gender, salary, type of job, and education was also collected from respondents along with information about average number of work hours generally performed per week including overtime and self-reported BMI. Caffeine consumption by beverage type and total caffeine consumption was calculated by allocating caffeine $/ \mathrm{mL}$ numerals using values for beverages in the AUSNUT 2011-13 AHS Food Nutrient Database (FSANZ 2011). Trades were categorized as finishing and formwork (e.g., painter, electrician, tiler, plasterer, plumber, window fixer, glazier, air conditioning, stone mason, cabinet maker) or initial and structural (carpenter, scaffolder, steel fixer, crane operator or dogman, bricklayer, blocklayer, concreter, laborer, stressor).

\section{Data Analysis Strategy}

The process used for analysis of the qualitative data formed a version of convergent interviewing as described by Jepsen and Rodwell (2008). Analytical conversations between the researchers were performed after the interviews at each site to identify preliminary themes and investigate concepts (Goetz and LeCompte 1981).

For quantitative data, bivariate logistic regression analyses were conducted to examine determinants of caffeine consumption. Caffeine consumption was dichotomized to those consuming more or less than the daily recommended maximum caffeine intake $(<210 \mathrm{mg} /$ day $)$.

Of the 250 surveys completed, there were 239 male and 6 female respondents (5 missing). Missing values were generally random, but age and salary appeared to have intentional noncompletion with 56 missing cases each (not the same cases). Missing drink data appeared unintentional with serving sizes sometimes missing. To reduce the impact of missing variables on power in the analyses, missing serving size values were replaced with the modal choice by cohort respondents or the most frequently available drink serving available on sites [using the serving size expertise of the project research dietitian (Katherine Markwell)]. Data were then analyzed in two different models; one with work conditions that were hypothesized to impact caffeine consumption (work hours, structural or finishing trades, complete data $n=156$ ) and one with these and demographic covariates included (age, salary, and selfreported body mass index, complete data $n=98$ ). Gender was excluded due to the low numbers of females. The separation into two models was to allow the investigation of work influences (work hours and trade type) while reducing the impact of missing demographic data for age and salary. There was low multicollinearity between trades or work hours (-r.173, $p=0.035)$. Descriptive 
frequencies and trends were also calculated. Analyses were performed in SPSS Version 22.

\section{Results}

\section{Quantitative Data}

Of the 156 surveys for the first model, there were 153 male respondents (98\%), 2 female respondents (1\%), and 1 missing response. Demographic characteristics of the sample along with caffeine consumption data are presented in Table 1.

Binary logistic regression analyses for caffeine consumption are shown in Tables 2 and 3. In Model 1 (Table 2), higher working hours were cross-sectionally associated with higher caffeine consumption $(\beta=-0.046, p=0.037)$. Trade type (structural or finishing) was not associated with caffeine consumption $(\beta=0.109$, $p=0.799$ ). In Model 2 (Table 3) with additional demographic covariates, higher working hours were still cross-sectionally associated with higher caffeine consumption $(\beta=-0.064, p<0.022)$.

A total of $31 \%$ of workers indicated that they consumed more than one energy drink a week and younger age was associated with this trend $(\beta=-0.035, p=0.017, n=214)$. The relationship between age and FCB consumption can be seen descriptively in Fig. 1.

\section{Qualitative Findings}

Thematic content analysis of interview data resulted in two main drivers of consumption consistent with the theory of reasoned action: Individual assessments of the degree to which caffeine and FCB consumption assists with managing time pressures and with managing daily work pressures in the short term and the long term. Negative views about mood fluctuations, attention, and safety

Table 1. Sample Characteristics $(n=156)$

$\mathrm{T} 1: 1$

$\mathrm{T} 1: 2$

$\mathrm{T} 1: 3$

$\mathrm{T} 1: 4$

$\mathrm{T} 1: 5$

$\mathrm{T} 1: 6$

$\mathrm{T} 1: 7$

$\mathrm{T} 1: 8$

$\mathrm{T} 1: 9$

$\mathrm{T} 1: 10$

$\mathrm{T} 1: 11$

$\mathrm{T} 1: 12$

$\mathrm{T} 1: 13$

$\mathrm{T} 1: 14$

$\mathrm{T} 1: 15$

$\mathrm{T} 1: 16$

$\mathrm{T} 1: 17$

\section{Variable}

Average age $[\mathrm{M}(\mathrm{SD})](n=129)$

Permanent staff $(\%)(n=154)$

Salary (\$/fortnight) $[\mathrm{M}(\mathrm{SD})](n=126)$

Highest level of education $(n=153)$

Completed high school or some secondary education (\%)

Completed trade or tertiary training $(\%)$

Self-reported BMI $\left(\mathrm{kg} / \mathrm{m}^{2}\right)[\mathrm{M}(\mathrm{SD})](n=142)$

Average daily caffeine consumption (mg/day) $[\mathrm{M}(\mathrm{SD})](n=156)$

Daily caffeine intake (mg/day) [median (range)]

Caffeine from FCBs ${ }^{\mathrm{a}}(\%)[\mathrm{M}(\mathrm{SD})](n=148)$

Caffeine from caffeinated soft drinks $(\%)[\mathrm{M}(\mathrm{SD})](n=148)$

Caffeine from coffee or tea (\%) [M (SD)] $(n=148)$

Caffeine consumption $>210 \mathrm{mg} /$ day $^{\mathrm{b}}(\%)(n=29)$

Working hours $[\mathrm{M}(\mathrm{SD})](n=156)$

Trades

Structural trades (formwork carpenters, scaffolders, steel fixers, crane operators,

bricklayers, blocklayers, concreters, laborers) $(\%)$

Finishing trades (painters, electricians, tilers, plasterers, plumbers) $(\%)$

Note: $n$ values are given if missing data; $\mathrm{M}=$ mean; $\mathrm{SD}=$ standard deviation.

${ }^{a}$ Values identified or averaged by the research dietitian (Katherine Markwell) using AUSNUT 2011-13 AHS Food Nutrient Database (FSANZ 2011); estimated values of FCBs $=32 \mathrm{mg} / 100 \mathrm{~g}$; caffeinated soft drinks $=9 \mathrm{mg} / 100 \mathrm{~g}$; coffee or tea $=$ mean $31.8 \mathrm{mg} / 100 \mathrm{~g}$.

${ }^{\mathrm{b}}$ Caffeine intake dichotomized to $\geq 210 \mathrm{mg}$ daily or $<210 \mathrm{mg}$ daily (Smith et al. 2000).

Table 2. Relationship between Trade Types and Work Hours with Caffeine Consumption Less Than or above 210 mg: Model 1

\begin{tabular}{|c|c|c|c|}
\hline \multirow[b]{2}{*}{ Predictor } & \multirow{2}{*}{$\begin{array}{c}B \text { (standard } \\
\text { error) }\end{array}$} & \multicolumn{2}{|c|}{ Daily caffeine consumption $(n=156)$} \\
\hline & & Wald & OR \\
\hline Trades (structural or finishing) & $0.109(0.429)$ & 0.105 & $1.116, p=0.799$ \\
\hline Weekly work hours (total) & $-0.046(0.022)$ & 4.727 & $0.955, p=0.037$ \\
\hline Full model & - & $R_{c s}^{2}=0.032, R_{N}^{2}=0.051, P=0.081$ & \\
\hline
\end{tabular}

Note: Significant $(p<0.05)$ associations appear in bold text; OR = odds ratio, adjusted.

Table 3. Summary of Binary Logistic Regression Analysis for Variables Predicting Caffeine Consumption, Controlling for Background Variables: Model 2

\begin{tabular}{|c|c|c|c|}
\hline \multirow[b]{2}{*}{ Predictor } & \multirow[b]{2}{*}{$B$ (standard error) } & \multicolumn{2}{|c|}{ Daily caffeine consumption $(n=98)$} \\
\hline & & Wald & OR \\
\hline$\overline{\text { Age (years) }}$ & $0.052(0.032)$ & 5.244 & $1.015, p=0.430 ; 1.053, p=0.107$ \\
\hline Salary (weekly) & $0.000(0.00)$ & 4.075 & $1.000, p=0.388 ; \mathbf{1 . 0 0 0}, \mathbf{p}=\mathbf{0 . 0 4 4}$ \\
\hline Trades (structural or finishing) & $-0.061(0.703)$ & 0.008 & $1.114, p=0.786 ; 0.940, p=0.930$ \\
\hline Weekly work hours (total) & $-0.064(0.028)$ & 5.244 & $0.964, p=0.070 ; \mathbf{0 . 9 3 8}, \mathbf{p}=\mathbf{0 . 0 2 2}$ \\
\hline BMI & $0.071(0.050)$ & 2.037 & $1.026, p=0.498 ; 1.074, p=0.153$ \\
\hline Full model & - & \multicolumn{2}{|c|}{$R_{c s}^{2}=0.107, R_{N}^{2}=0.197, \mathbf{P}=\mathbf{0 . 0 5 0}$} \\
\hline
\end{tabular}

Note: Significant $(p<0.05)$ associations appear in bold text; OR $=$ odds ratio, raw and adjusted. 


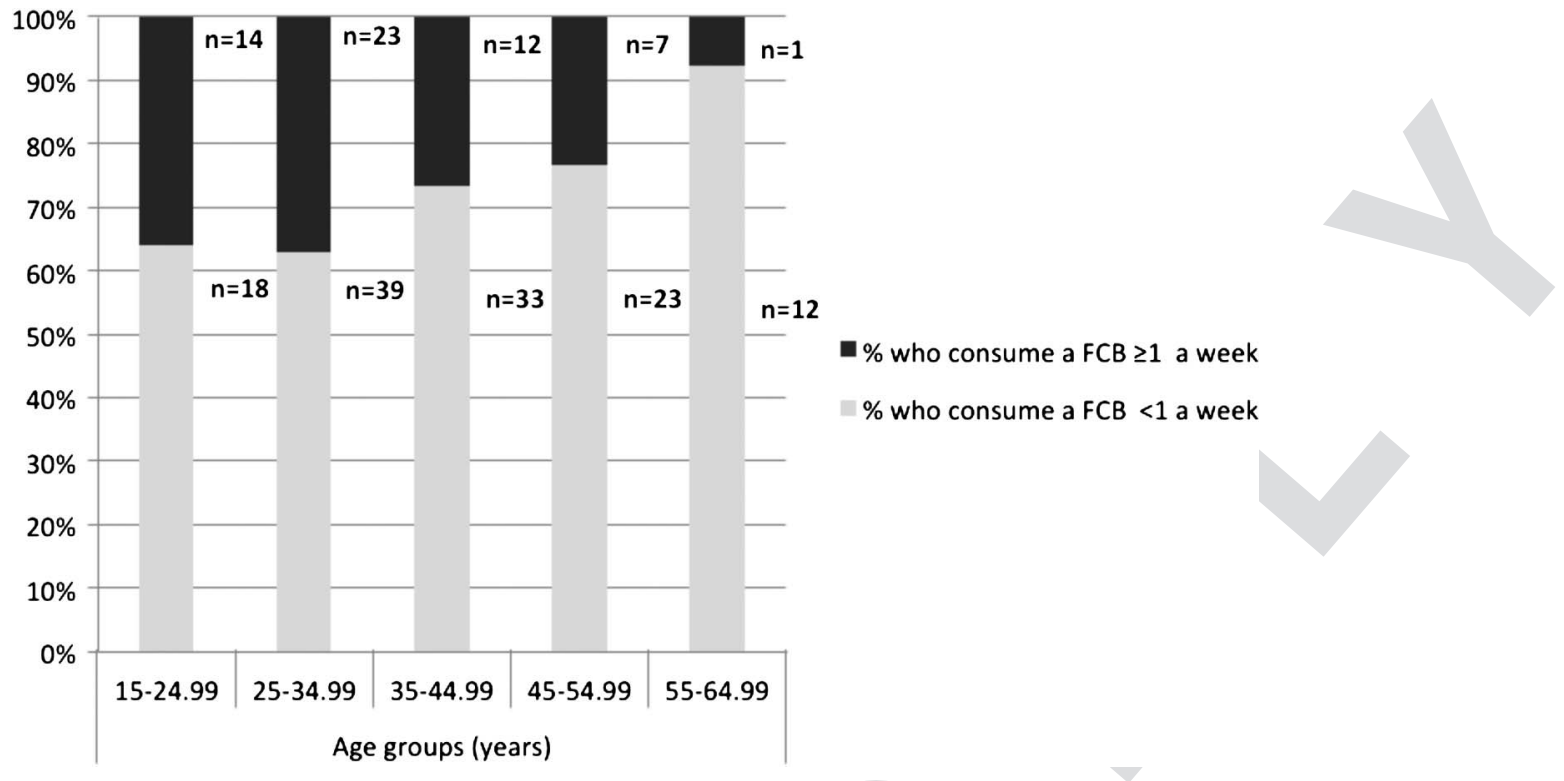

Fig. 1. Age groups and FCB consumption frequency $(n=182)$

impacts on site associated with hydration were identified as deterrents for consumption.

Interview data highlight the increasing role FCBs play in construction. A common view expressed by site managers was that energy drinks are the norm. One site manager considered the influence of energy drinks as so persuasive that it had taken over from the traditional soft drink and cigarette culture onsite. As he explained: "The energy drinks are a change, used to be Coke and cigarettes, but smoking is banned on site now and the energy drinks are new."

There were consistently held views by managers and workers that FCBs affected the performance of people on site, with people consuming multiple drinks throughout the day being easy to identify. One site manager noted: "You can really tell the ones on the energy drinks. They are wired and talkative by the end of the day."

And a plasterer: "You can tell the people on the energy drinks. Their body language gives it away-pacing and agitation and the crap they talk; their appearance too."

Generally, although workers noted that those consuming energy drinks were difficult to work with, only managers expressed concern about the impact of increasing consumption on workers and on safety on site. These concerns largely centered around workers' long-term general health and also on more immediate concerns about hydration onsite. This concern about hydration resulted in most managers thinking energy drink consumption did or could fall within their area of responsibility. The impact of energy drinks on weight and broader health indexes, however, were not generally perceived as safety risks by both workers and managers and were considered an individual's responsibility as noted by the following managers:

[Energy drinks] ah, that's more of a, a health risk. That's more of an occupational health and safety thing for me if you know what I mean. You get high on those things and when you come down, you become very very down you know.

I've got some guys who I actually believe they're energy drink addicts, and I do speak to them about it, but once again, $98 \%$ of the time like... it's laughter is the reply. Once again, that's a hydration thing for me. The energy drinks actually have the opposite effect, they do, I'm pretty sure it's proven, dehydrate. rather than rehydrate, so I try to get them to cut down. Obviously I can't stop them, but I try to get them to cut down and drink more water. That's part of my role here definitely, just to keep them on their feet all day.

Due to the perceived risk of safety incidents, one subcontractor company had implemented rules against energy drink consumption. As their manager explained, "I find a fair few people drinking energy drinks um, like it's water. My employees, don't, aren't allowed to drink energy drinks, when it's hot they just drink, really too much of them. It just makes you more thirsty, your body's going a hundred miles an hour. You know that stuff's not good for you. Because we had a fair few, um, fair few incidents with them.... There's quite a lot of concreters, they drink a lot of it they get hot and sweaty and don't enough, you know, water, they just collapse. Overexert yourself."

Importantly, while not every manager and worker expressed concern over the amount of FCBs consumed on site, no one interviewed indicated that they had a positive impact on performance or well-being beyond a few noting they helped them temporarily when they felt sluggish.

Supporting the survey trends in Fig. 1, the consumption of FCBs was seen by most as more common for less experienced and younger workers than older workers, possibly reflecting advertising campaigns targeted at young people but also a lack of experience. As one site manager explained, "You see the young blokes smashing pies and energy drinks every day. The older blokes are more experienced and know what makes them feel good. When you're young you've got iron guts and (you think you're) invincible."

And older trades workers:

The younger generation - say under 30 and apprentices-live on Red Bull. They have 1-2 a day. Certainly energy or hipster drinks replace food.

When the young guys come on site, first thing in the morning and they've got two "Red Bulls" in their hands, they're full of energy. And then by 10 o'clock they are miserable and want to go home

Looking at drivers for FCB consumption patterns on site, reasons cited generally revolved around stress and attempts to manage the pace, timing, and intensity of work. 


\section{Time Pressures}

The first area that workers reported turning to energy drinks relates to the early start times combined with long work hours and long commutes to work. Numerous workers indicated they often feel time and workload pressures due to deadlines, and this has a real influence on their decision making on a daily basis. Interviewees explained that energy drinks are replacing breakfast or other meals so that they can sleep a little longer or because they are not organized to have breakfast, as noted by the following managers:

I've got some guys I know who don't eat bugger all all day but they do survive on the Red Bulls.

They've got some though that don't even eat-energy drinks and one big dinner. One of the guys is 19 and he drinks energy drinks all day then a big dinner.

And trades workers themselves: "Energy drinks a huge for breakfast. Quick, easy, and make you feel good-for a while anyway. We get energy drinks at the servo."

The nature of working hours within the industry, combined with employees often working on projects at least $1 \mathrm{~h}$ of driving time from their house, meant that 4-4:30 a.m. was a common wake-up time for these workers. Numerous employees said their body is not ready for food at 4 a.m. and the long commute and work days provided an added stress influencing the time and energy available to eat breakfast. For some, energy drinks were consumed as a caffeine pickup particularly on the long drive home. As these trades workers explained, "It is a high energy job and early starts so it is tempting to skip breakfast. Getting up $1 / 2$ hour is hard. I eat on the run. When I eat breakfast so early it just feels like an extra meal so I get hungry as if I haven't had it anyway. Coffee or energy drinks get people through the day."

Because of time pressures, convenience when making beverage choices was reported to impact consumption as noted by these managers: "A lot of people they work long hours they're tired when they get home. [The] last thing they'll think about is making a healthy lunch. Not laziness, that's probably the wrong word for it, tiredness."

\section{Work Pressure}

The second driver of FCB consumption identified in the data was beliefs about strategies to manage workload work pressure. It was very clear from the interviews that workers used FCBs in an attempt to cope with stress associated with work pressure, particularly the physical requirements of their job. These are decisions that had a direct impact on drinking habits as noted by these trades workers:

They find they've got to do it [drink energy drinks], because they're pushed, they're pushed to do everything fast. They're still working hard but they're ... well you know, the foreman can only influence them for so long before your body gets tired, instead of slowing up-there's no room for that you know-take something and make yourself continue at that level.

People definitively need the sugar rush of Coke or energy drinks.

Most managers described seeing energy drinks as a short-term fix with the end result being a cycle of multiple drinks being consumed throughout the day: "If their energy is running out they might grab an energy drink but they're a quick fix - you then need another one in an hour."
This view was supported by many trades workers themselves: "You've just had that energy drink-you'll be $100 \%$ of 10 min then you'll crash."

Coupled with this comment, the habit-forming or addictive aspect of energy drinks was a concern for some trades workers: "Fatigue, tiredness, wanting a sugar boost. It becomes a habit you can't get out of."

\section{Discussion}

This study provides a detailed picture of energy drink and caffeine consumption on urban Australian project construction sites. Results indicate that energy drinks are consumed widely and regularly on site, with stress and attempts to manage the pace, timing, and intensity seen as drivers for consumption. Although FCBs are consumed on worksites and are consumed by younger workers as reported by both the quantitative and qualitative data, at this point age is not the main contributor to caffeine intake. The most important trend was that caffeine consumption is associated with greater work hours. This became significant with trade types included in the model; work hours are likely to be influenced by trade type and this by extension influences caffeine consumption. It is clear from both the quantitative and qualitative data that caffeine usage appears to be used by construction workers to modify and cope with working conditions. This should be considered in planning health promotion interventions and preventing longer-term health issues on construction sites.

These findings suggest the theory of reasoned action (Ajzen and Fishbein 1980) represents a useful guiding framework to explain FCB consumption in construction. Results indicate that positive personal judgments about caffeine and FCBs assisting with managing time pressures and daily work pressures in the short term and the long term represent important components of the motivation to drink. Conversely, negative judgments about mood fluctuations, attention, and safety impacts on site associated with hydration represent important components of the motivation to restrain from consumption. The disparity between evidence on the risks posed by FCB consumption and the perceptions of workers reported in this study about their perceived benefits suggests there is an opportunity for education strategies to influence personal judgments.

The findings here point to interactions between the organization of work and health behaviors on site by way of beverage choices. Healthy work organization has received growing attention in recent years, including some construction sites, largely owing to the growing recognition and understanding of the determinants of these environments and organizational costs when they are not managed (Story et al. 2008). It focuses on the impact of the structure and management of work processes-such as job design, scheduling, management, organizational characteristics, and policies and procedures - on the health and well-being of employees creating healthy or unhealthy work systems (DeJoy et al. 2006, 2010). Broad research shows that stressful work environments and associated work-life interference are directly related to higher levels of sickness absence and increased turnover (Bergström et al. 2007), and, at an individual level to psychological strain, psychiatric disorders and substance abuse (Carlson et al. 2011; Hammer et al. 2004; Siegrist 2008; van den Berg et al. 2008). These findings extend this research by showing that work organization is associated with FCB consumption. Construction workers and managers in this sample identified work organizational influences that underpin health behaviors on site, with an obvious example being the presence of vending machines stocking FCBs on construction sites in Australia (Townsend et al. 2016). 
In many countries there is a lack of regulation with FCBs. In the United States, public health measures including improved labeling, regulation, and education have been advocated (Arria and O'Brien 2011; Thorlton et al. 2014). Such discussions have led to industry concerns of product liability and suggestions for prophylactic action (Peterson 2013). In Australia, the situation is dissimilar, with labeling and regulations being more stringent. Food Standards Australia New Zealand require formulated caffeinated beverages to be labeled with warnings about caffeine consumption and suggested maximal consumption (Code Standard 2.6.4). While this is higher than that of other caffeinated soft drinks, it is not unregulated. However, findings here suggest these regulations are not effective in preventing overconsumption of FCBs for construction workers, who report using these drinks to try to manage their stressful working environment and as an alternative breakfast.

The nature of project-based work in construction presents considerable challenges for work hours. There are usually long working hours, early start times, 6-day working weeks, and potentially long commute times depending on site location changes. Long working hours and early start times are associated with reduced sleep times (Basner et al. 2013; Chatzitheochari and Arber 2009). Managers in this study did not raise sleep loss as a concernalthough this may reflect a lack of knowledge of the impacts-but prolonged sleep loss has been identified to impact multiple health parameters including depression and chronic diseases (PorkkaHeiskanen et al. 2013).

Construction workers are not generally considered shift workers unless their shift schedules include nightwork. However, these exposures indicate that construction workers may be more likely to accumulate a sleep debt than day-shift workers with later start times and a shorter shift. Previously cited reasons for FCB consumption include overcoming fatigue and improving physical performance, particularly among those on atypical schedules (Jay et al. 2006; Malinauskas et al. 2007; Stephens et al. 2014). Results here suggest construction workers have similar perceived reasons to use FCBs; that is, positive beliefs about consumption assisting with overcoming fatigue associated with work schedules and the generally physical nature of the work, and to improve performance. Marketing FCBs as energy drinks is one explanation of where these beliefs might stem. Additionally, the workforce is generally younger and male - the target group for FCB marketing - so any risks of consumption may be disproportionate compared with risks of consumption in the general population.

The reported performance benefits of caffeine consumption may be due to supplying a substance from which the body is withdrawing, rather than independent improvements, per se (James and Rogers 2005) so irregular and changing caffeine consumption, as potentially seen within changing daily work hours in construction, may impact productivity and safety through physiological mechanisms more than a steady dose of caffeine consumption. Caution is therefore advised in consumption. Portion sizes have increased in some FCB brands along with availability on site, increasing the likelihood of consuming more caffeine. Without this easy access, workers would otherwise have required prior purchase to consume them, a difficult task in the short and infrequent work breaks described by many workers.

Like alcohol, excessive consumption of caffeine is a known risk for heat stress (Rowlinson et al. 2014). Prevention of heat stress is important for subtropical working conditions as seen in many parts of Australia. Results indicate that the impact of FCB consumption on hydration and associated heat stress are of concern for managers in construction and something they see as part of their responsibility to manage. Caffeine has many physiological effects and has been recommended for athletes to improve sports performance
(Goldstein et al. 2010), but some argue that on balance FCBs should not be consumed during sport (Higgins et al. 2000). For a physical work setting where hydration affects cognition and safety risks, similarly FCBs are not ideal. Further, it should be considered that while sources of caffeine such as tea and coffee have components that have known cancer-prevention effects, FCBs and caffeinated soft drinks do not because caffeine is a supplement to the beverage and the other main component besides water is added sugar, also known to be detrimental to health outcomes. It is unknown if FCBs have displaced drinks that were similar in caffeine content in Australian diets (e.g., a can of Coke) or noncaffeinated beverages (e.g., water, regular soft drink, juice). Caffeinated energy drinks are categorized as sugar-sweetened beverages (SSBs), the consumption of which contribute to weight gain and chronic disease risk including cardiovascular diseases (Hu and Malik 2010; Malik et al. 2010). The construction industry has a higher than average risk of CVD due to predisposing risk factors (Alwan 2011). Thereby, their regular and high usage of energy drinks could further exacerbate workers' elevated risk of developing CVD. From the viewpoint of worker physical health and work health and safety, FCBs as a source of excessive energy may pose other risks, with obesity being linked to greater accidents in other industries (Anderson et al. 2012) and having other potential health and safety risks identified in a review by Schulte et al. (2008).

A limitation of this study is that daily caffeine consumption and work hours were based on self-reported data and that there were a large amount of missing demographic data, particularly age and salary. This Is not surprising given both are likely to be sensitive in the industry owing to the unreliable nature of work and the physical nature of many jobs making age discrimination more likely (Van Dalen et al. 2010). Despite these limitations, caffeine is commonly known and used as a performance enhancer for fatigue so the observed relationships between higher working hours with higher caffeine consumption appear plausible. Further investigation of single daily consumption and work hour records may show even stronger trends in daily variation related to work load. If there is daily variance in the consumption of caffeinated beverages (including FCBs), physiological effects around performance, sleep, and mood will vary with respect to length of caffeine abstinence and tolerance.

\section{Conclusion}

This study is part of a growing body of literature investigating poor health behaviors in construction and identifies drivers of a risky new trend in construction, excessive FCB consumption. It also extends previous literature by considering the role of managers and workers in encouraging or discouraging poor lifestyle choices in construction. The theory of reasoned action provided insight into understanding motivators to consume or restrain from consuming FCBs in construction.

Many managers and workers alike indicated concern about excessive FCB on site, particularly for young male workers. These concerns largely centered on long-term workability in the industry, but also extended to short-term concerns around dehydration, fatigue, and reduced alertness at work. Motivators for excessive consumption centered on beliefs that FCBs can assist with managing time pressures and daily work pressures. Managers indicated that while many see managing FCB consumption as part of their responsibility, they find it difficult to persuade their workforce to take their concerns seriously, possibly as a result of a lack of understanding about the impact of excessive consumption on site. 
Future research can use this information to identify behavior change opportunities among different groups of workers in the construction work environment. It can be concluded from this study that raising the profile of FCBs on site to make links between excessive consumption and safety on site clearer is likely to be a key leverage point for managers aiming to improve current practices and ensure the health of their workers. As such, the findings inform current practices for managing a workforce in this unique work environment where maximum productivity requirements, brought about by strict production targets and penalties for noncompliance, are critical (Lingard et al. 2012). Evidence indicates that long-term employment in construction is problematic, in part owing to increased risks for developing chronic diseases (DEEWR 2011; Sedighi and Loosemore 2012). Taking a more informed and holistic approach to managing construction workers will have benefits for individual firms and for longevity in the industry more broadly.

Arguably the next step of improving workers' risk profiles in these industries is reducing unhealthy lifestyle choices such as consuming excessive amounts of FCBs. While there are specific characteristics of construction work environments that may contribute to increased health risks (stress, mental illness, long hours, and/or reduced sleep), drinking habits are an acknowledged key factor that influences health outcomes. Formulated caffeinated beverage intake is also considered a potential safety concern in hot climates on construction sites and separate to nutritional issues. In combination, the findings here support previous research emphasizing the need for research on health as well as safety in the construction environment (Loudoun et al. 2017) and suggest that attention is particularly needed to address this risky new trend in construction.

As the third highest paid sector in Australia (ABS 2013), it is reasonable to assume the health benefits associated with higher economic status to be present in this group, however this is not the case. Male blue-collar workers in Australia have "poorer than average health outcomes, increased mortality rates, disability, and serious chronic disease" (Kolmet et al. 2006, p. 82). Safety has always been of considerable interest on construction sites, but the continuing poor occupational health of employees and the interaction between the construction work environment, behavioral responses from workers, and the multifaceted implications these responses have on health and safety have received less consideration. There has been a growing interest in improving the health of workers in general, with the majority of large employers now offering wellness programs (Mattke et al. 2013). Alcohol use generally forms part of health campaigns in construction aimed at improving health behaviors. The results of this study suggest these campaigns, and research on health behaviors more generally in construction, should be extended to included FCBs.

\section{Data Availability Statement}

Data generated or analyzed during the study are available from the corresponding author by request. Information about the Journal's data sharing policy can be found here: http://ascelibrary.org/doi/10 $.1061 / \% 28$ ASCE\%29CO.1943-7862.0001263.

\section{References}

ABS (Australian Bureau of Statistics). (2011). 2011 census of population and housing, Canberra, Australia.

ABS (Australian Bureau of Statistics). (2012). Australian health survey: Nutrition first results-Foods and nutrients, 2011-12, Canberra, Australia.
ABS (Australian Bureau of Statistics). (2013). Employee earnings and hours, Canberra, Australia.

Abowitz, D., and Toole, T. (2010). "Mixed method research: fundamental issues of design, validity, and reliability in construction research." J. Constr. Eng. Manage., 10.1061/(ASCE)CO.1943-7862.0000026, $108-116$.

Alwan, A. (2011). Global status report on noncommunicable diseases 2010, World Health Organization, Geneva.

Anderson, J. E., et al. (2012). "Obesity is associated with the future risk of heavy truck crashes among newly recruited commercial drivers." Accid. Anal. Prev., 49, 378-384.

Andreyeva, T., Long, M. W., and Brownell, K. D. (2010). "The impact of food prices on consumption: a systematic review of research on the price elasticity of demand for food." Am. J. Public Health, 100(2), 216-222.

Arria, A. M., Caldeira, K. M., Kasperski, S. J., Vincent, K. B., Griffiths, R. R., and O'Grady, K. E. (2011). "Energy drink consumption and increased risk for alcohol dependence." Alcohol.: Clin. Exp. Res., 35(2), 365-375.

Arria, A. M., and O'Brien, M. (2011). "The 'high' risk of energy drinks." JAMA, 305(6), 600-601.

Australian Institute of Health and Welfare. (2011). "2010 National Drug Strategy Household Survey report." Drug Statistics Series No. 25, Cat. No. PHE 145, Canberra, Australia.

Basner, M., Spaeth, A. M., and Dinges, D. F. (2013). "Sociodemographic characteristics and waking activities and their role in the timing and duration of sleep." Sleep, 37(12), 1889-1906.

Bergström, G., Bodin, L., Bertilsson, H., and Jensen, I. B. (2007). "Risk factors for new episodes of sick leave due to neck or back pain in a working population. A prospective study with an 18-month and a threeyear follow-up." J. Occup. Environ. Med., 64(4), 279-287.

Berry, J. G., Pidd, K., Roche, A. M., and Harrison, J. E. (2007). "Prevalence and patterns of alcohol use in the Australian workforce: Findings from the 2001 National Drug Strategy Household Survey." Addiction, 102(9), 1399-1410.

Bowen, P., Edwards, P., Lingard, H., and Cattell, K. (2013). "Workplace stress, stress effects, and coping mechanisms in the construction industry." J. Constr. Eng. Manage., 10.1061/(ASCE)CO.1943-7862 .0000807, 04013059

Bragger, J. D., Rodriguez-Srednicki, O., Kutcher, E. J., Indovino, L., and Rosner, E. (2005). "Work-family conflict, work-family culture, and organizational citizenship behavior among teachers." J. Bus. Psychol., 20(2), 303-324.

Canadean. (2011). "Canadean soft drink service-Australia and New Zealand energy drink consumption volumes 1999-2016."

Carlson, D. S., Grzywacz, J. G., Ferguson, M., Hunter, E. M., Clinch, C. R., and Arcury, T. A. (2011). "Health and turnover of working mothers after childbirth via the work-family interface: An analysis across time." J. Appl. Psychol., 96(5), 1045-1054.

Chan, I., Leung, M., and Yu, S. (2012). "Managing the stress of Hong Kong expatriate construction professionals in mainland China: Focus group study exploring individual coping strategies and organizational support." J. Constr. Eng. Manage., 10.1061/(ASCE)CO.1943-7862 $.0000533,1150-1160$.

Chatzitheochari, S., and Arber, S. (2009). "Lack of sleep, work and the long hours culture: Evidence from the UK time use survey." Work Employment Soc., 23(1), 30-48.

Conger, J. J. (1951). "The effects of alcohol on conflict behavior in the albino rat." Q. J. Stud. Alcohol, 12, 1-49.

Courtenay, W. H. (2000). "Engendering health: A social constructionist examination of men's health beliefs and behaviours." Psychol. Men Masculinity, 1(1), 4-15.

Creswell, J. W. (2007). Qualitative inquiry and research design: Choosing among five approaches, 2nd Ed., Sage, Thousand Oaks, CA.

DEEWR (Dept. of Education Employment and Workplace Relations). (2011). "Employment and workplace relations 2011." Skills Info Construction Industry Rep., Canberra, Australia.

DeJoy, D. M., Wilson, M. G., and Griffin-Blake, C. S. (2006). "Healthy work organization." International encyclopedia of ergonomics and human factors, 2nd Ed., W. Karwowski, ed., Taylor and Francis, London. 
DeJoy, D. M., Wilson, M. G., Vandenberg, R. J., McGrath-Higgins, A. L., and Griffin-Blake, C. S. (2010). "Assessing the impact of healthy work organization intervention.” J. Occup. Org. Psychol., 83(1), 139-165.

Fishbein, M. (2008). "A reasoned action approach to health promotion." Med. Decis. Making, 28(6), 834-844.

Flegal, K. M., Carroll, M. D., Kit, B. K., and Ogden, C. L. (2012). "Prevalence of obesity and trends in the distribution of body mass index among US adults, 1999-2010." JAMA, 307(5), 491-497.

Fontana, A., and Frey, J. H. (1994). Handbook of qualitative research, Sage, Thousand Oaks, CA.

FSANZ (Food Standards Australia New Zealand). (2011). "AUSNUT 2011-13 food nutrient database." 〈http://www.foodstandards.gov.au /science/monitoringnutrients/ausnut/ausnutdatafiles/Pages/foodnutrient .aspx> (Nov. 2, 2015).

FSANZ (Food Standards Australia New Zealand). (2014). "Warning and advisory statements and declarations." User guide to standard 1.2.3Mandatory warning and advisory statements and declarations.

Godin, G., and Kok, G. (1996). "The theory of planned behavior: a review of its applications to health-related behaviors." Am. J. Health Promotion, 11(2), 87-98.

Goetz, J., and LeCompte, M. (1981). "Ethnographic research and the problem of data reduction." Anthropol. Educ. Q., 12(1), 51-70.

Goldstein, E. R., et al. (2010). "International society of sports nutrition position stand: Caffeine and performance." J. Int. Soc. Sports Nutr., 7(1), 5 .

Gunja, N., and Brown, J. A. (2012). "Energy drinks: Health risks and toxicity." Med. J. Australia, 196(1), 46-49.

Hammer, T. H., Saksvik, P. Ø., Nytrø, K., Torvatn, H., and Bayazit, M. (2004). "Expanding the psychosocial work environment: Workplace norms and work-family conflict as correlates of stress and health." J. Occup. Health Psychol., 9(1), 83-97.

Hausenblas, H. A., Carron, A. V., and Mack, D. E. (1997). “Application of the theories of reasoned action and planned behavior to exercise behavior: A meta-analysis." J. Sport Exerc Psychol, 19(1), 36-51.

Head, K. J., and Noar, S. M. (2014). "Facilitating progress in health behaviour theory development and modification: The reasoned action approach as a case study." Health Psychol. Rev., 8(1), 34-52.

Hector, D., Rangan, A., Louie, J., Flood, V., and Gill, T. (2009). "Soft drinks, weight status and health: A review. Sydney: A NSW Centre for Public Health Nutrition (now known as Cluster of Public Health Nutrition, Prevention Research Collaboration, Univ. of Sydney) project for NSW Health."

Hedrick, V. E., et al. (2012). "Development of a brief questionnaire to assess habitual beverage intake (BEVQ-15): Sugar-sweetened beverages and total beverage energy intake." J. Acad. Nutr. Dietetics, 112(6), 840-849.

Hengel, K. M. O., Blatter, B. M., van der Molen, H. F., Bongers, P. M., and van der Beek, A. J. (2013). "The effectiveness of a construction worksite prevention program on work ability, health, and sick leave: Results from a cluster randomized controlled trial." Scandinavian J. Work Environ. Health, 39(5), 456-467.

Higgins, J. P., Tuttle, T. D., and Higgins, C. L. (2000). "Energy beverages: content and safety." Mayo Clinic Proc., Elsevier, Netherlands.

Hu, F. B., and Malik, V. S. (2010). "Sugar-sweetened beverages and risk of obesity and Type 2 diabetes: Epidemiologic evidence." Physiol. Behav., $100(1), 47-54$.

Iles, R. A., Wyatt, M., and Pransky, G. J (2012). "Multi-faceted case management: Reducing compensation costs of musculoskeletal work injuries in Australia." J. Occup. Rehabil., 22(4), 478-488.

James, J. E., and Rogers, P. J. (2005). "Effects of caffeine on performance and mood: Withdrawal reversal is the most plausible explanation." Psychopharmacol., 182(1), 1-8.

Jay, S. M., Petrilli, R. M., Ferguson, S. A., Dawson, D., and Lamond, N. (2006). "The suitability of a caffeinated energy drink for night-shift workers." Physiol. Behav., 87(5), 925-931.

Jepsen, D., and Rodwell, J. (2008). "Convergent interviewing: A qualitative diagnostic technique for researchers." Manage. Res. News, 31(9), 650-658.
Kolmet, M., Marino, R., and Plummer, D. (2006). "Anglo-Australian male blue-collar workers discuss gender and health issues." Int. J. Men's Health, 5(1), 81-91.

Landolt, H-P., et al. (2004). "Caffeine attenuates waking and sleep electroencephalographic markers of sleep homeostasis in humans." Neuropsychopharmacol., 29(10), 1933-1939.

Levant, R. F., Wimer, D. J., Williams, C. M., Smalley, K. B., and Noronha, D. (2009). "The relationship between masculinity variables, health risk behaviors and attitudes towards seeking psychological help." Int. J. Men's Health, 8(1), 3-21.

Lingard, H., Francis, V., and Turner, M. (2012). "Work-life strategies in the Australian construction industry: Implementation issues in a dynamic project-based work environment." Int. J. Project Manage., 30(3), 282-295.

Lingard, H., Townsend, K., Bradley, L., and Brown, K. (2008). "Alternative work schedule interventions in the Australian construction industry: A comparative case study analysis." Constr. Manage. Econ., 26(10), 1101-1112.

Loudoun, R. (2010). "Injuries sustained by young males in construction during day and night work." Constr. Manage. Econ., 28(12), 1313-1320.

Loudoun, R., Townsend, K., and Markwell, K. (2017). "Implementing health promotion programs in the Australian construction industry: Levers and agents for change." Eng. Constr. Archit. Manage., 24(2).

Love, P., Edwards, D., and Irani, Z. (2010). "Work stress, support and mental health in construction." J. Constr. Eng. Manage., 10.1061 /(ASCE)CO.1943-7862.0000165, 650-658.

Malik, V. S., Popkin, B. M., Bray, G. A., Després, J. P., and Hu, F. B. (2010). "Sugar-sweetened beverages, obesity, Type 2 diabetes mellitus, and cardiovascular disease risk." Circulation, 121(11), 1356-1364.

Malinauskas, B. M., Aeby, V. G., Overton, R. F., Carpenter-Aeby, T., and Barber-Heidal, K. (2007). "A survey of energy drink consumption patterns among college students." Nutr. J., 6(1), 35-41.

Mattke, S., et al. (2013). Workplace wellness programs study, Rand Corporation.

Miller, K. E. (2008). "Wired: Energy drinks, jock identity, masculine norms, and risk taking." J. Am. College Health, 56(5), 481-490.

Onwuegbuzie, A., and Leech, N. (2005). "On becoming a pragmatic researcher: The importance of combining quantitative and qualitative research methodologies." Int. J. Soc. Res. Methodol., 8(5), 375-387.

Pabst, A., Baumeister, S. E., and Kraus, L. (2010). "Alcohol-expectancy dimensions and alcohol consumption at different ages in the general population." J. Stud. Alcohol Drugs, 71(1), 46-53.

Peterson, E. A. (2013). "Caffeine catastrophe: Energy drinks, products liability and market strategy." Int. J. Marketing Stud., 5(2), 50-58.

Pollard, C. M., McStay, C. L., and Meng, X. (2015). "Public concern about the sale of high-caffeine drinks to children 12 years or younger: An Australian regulatory perspective." BioMed. Res. Int., 8.

Porkka-Heiskanen, T., Zitting, K.-M., and Wigren, H.-K. (2013). "Sleep, its regulation and possible mechanisms of sleep disturbances." Actc Physiologica, 208(4), 311-328.

Reissig, C. J., Strain, E. C., and Griffiths, R. R. (2009). "Caffeinated energy drinks-A growing problem." Drug Alcohol Depend., 99(1), 1-10.

Roehrs, T., and Roth, T. (2008). "Caffeine: Sleep and daytime sleepiness." Sleep Med. Rev., 12(2), 153-162.

Rowlinson, S., Yunyanjia, A., Li, B., and ChuanjingJu, C. (2014). "Management of climatic heat stress risk in construction: a review of practices, methodologies, and future research." Accid. Anal. Prev., 66, 187-198.

Safe Work Australia. (2012). Compendium of workers' compensation statistics Australia 2009-10, Canberra, Australia.

Schulte, P. A., Wagner, G. R., Downes, A., and Miller, D. B. (2008). "A framework for the concurrent consideration of occupational hazards and obesity." Ann. Occup. Hyg., 52(7), 555-566.

Sedighi, F., and Loosemore, M. (2012). "Employer-of-choice characteristics in the construction industry." Constr. Manage. Econ., 30(11), 941-950.

Siegrist, J. (2008). "Chronic psychosocial stress at work and risk of depression: Evidence from prospective studies." Eur. Arch. Psych. Clin. Neurosci., 258(S5), 115-119. 


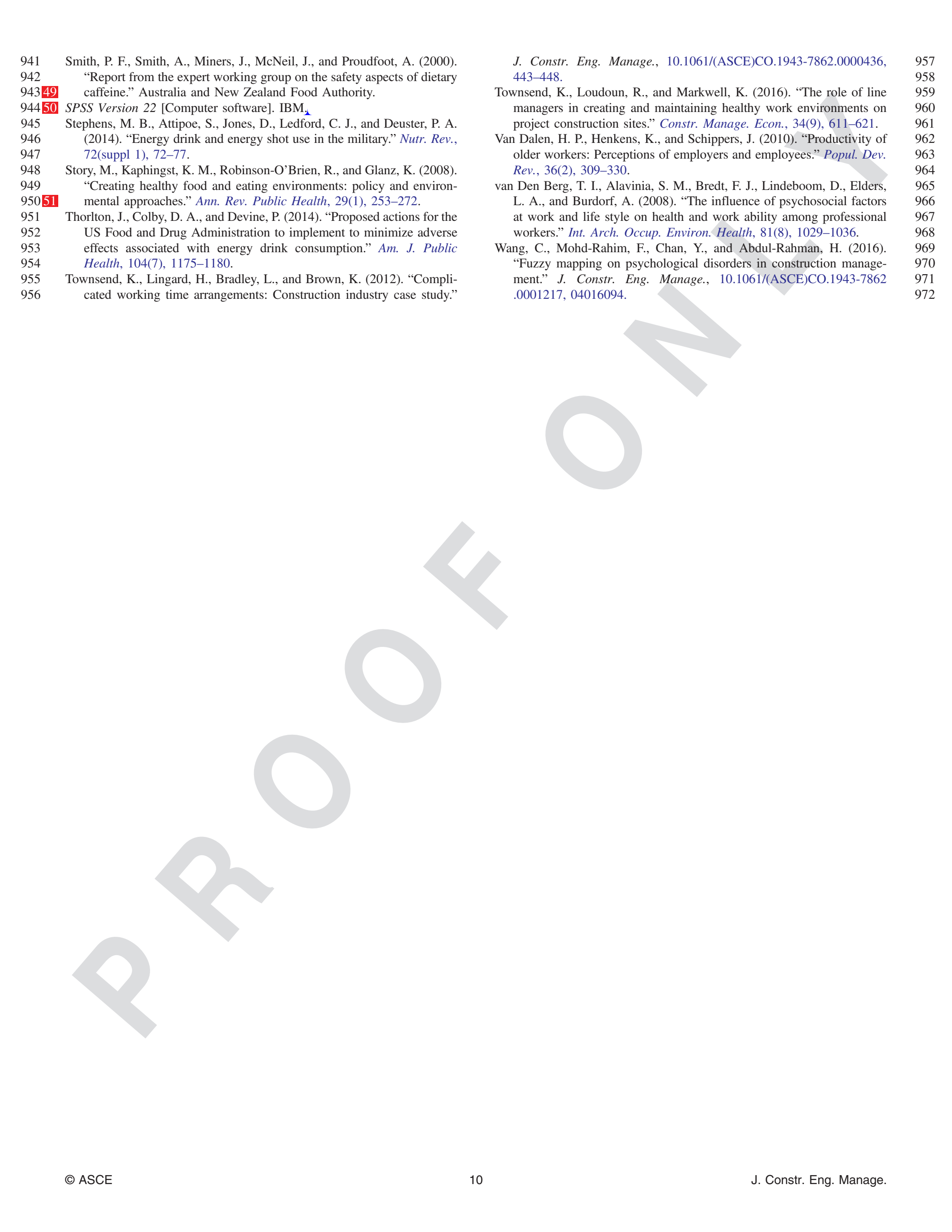

